\title{
Analgesic efficacy of lidocaine and multimodal analgesia for chest tube removal: A randomized trial study ${ }^{1}$
}

\author{
Valdecy Ferreira de Oliveira Pinheiro² \\ José Madson Vidal da Costa ${ }^{3}$ \\ Marcelo Matos Cascudo ${ }^{3}$ \\ Ênio de Oliveira Pinheiro ${ }^{3}$ \\ Maria Angela Ferreira Fernandes ${ }^{4}$ \\ Ivonete Batista de Araujo ${ }^{5}$
}

Objective: to assess the analgesic efficacy of subcutaneous lidocaine and multimodal analgesia for chest tube removal following heart surgery. Methods: sixty volunteers were randomly allocated in two groups; 30 participants in the experimental group were given 1\% subcutaneous lidocaine, and 30 controls were given a multimodal analgesia regime comprising systemic antiinflammatory agents and opioids. The intensity and quality of pain and trait and state anxiety were assessed. The association between independent variables and final outcome was assessed by means of the Chi-squared test with Yates' correction and Fisher's exact test. Results: the groups did not exhibit significant difference with respect to the intensity of pain upon chest tube removal $(p=0.47)$. The most frequent descriptors of pain reported by the participants were pressing, sharp, pricking, burning and unbearable. Conclusion: the present study suggests that the analgesic effect of the subcutaneous administration of $1 \%$ lidocaine combined with multimodal analgesia is most efficacious.

Descriptors: Pain Management; Chest Tubes; Analgesia.

\footnotetext{
1 Paper extracted from doctoral dissertation "Avaliação da eficácia analgésica da associação entre anestesia geral e raquianestesia com morfina combinada à ropivacaína a 0,5\% em relação à anestesia geral e analgesia multimodal no pós-operatório de revascularização do miocárdio", presented to Universidade Federal do Rio Grande do Norte, Natal, RN, Brazil.

2 PhD, Adjunct Professor, Departamento de Enfermagem, Universidade Federal do Rio Grande do Norte, Natal, RN, Brazil.

3 Physician, Hospital Promater, Natal, RN, Brazil.

${ }^{4} \mathrm{PhD}$, Adjunct Professor, Departamento de Odontologia, Universidade Federal do Rio Grande do Norte, Natal, RN, Brazil.

5 PhD, Adjunct Professor, Departamento de Farmácia, Universidade Federal do Rio Grande do Norte, Natal, RN, Brazil.
}

Corresponding Author:

Valdecy Ferreira de Oliveira Pinheiro Universidade Federal do Rio Grande do Norte Departamento de Enfermagem Av. Senador Salgado Filho, 3000 Bairro: Lagoa Nova

CEP: 59078-970, Natal, RN, Brasil

E-mail: valdecyfopinheiro@gmail.com
Copyright @ 2015 Revista Latino-Americana de Enfermagem This is an Open Access article distributed under the terms of the Creative Commons Attribution Non-Commercial License (CC BY-NC).

This license lets others distribute, remix, tweak, and build upon your work non-commercially, and although their new works must also acknowledge you and be non-commercial, they don't have to license their derivative works on the same terms. 


\section{Introduction}

The use of chest tubes is aimed to preserve hemodynamic stability and cardiopulmonary function by draining fluids, blood and air from the pleural, pericardial or mediastinal cavities $^{(1)}$. Removing chest tubes is painful, largely because the visceral pericardium and pleura are rich in nociceptive fibers ${ }^{(2)}$. The removal of chest tubes represents a potential stimulus for the intercostal nerve fibers that innervate the parietal pleura, chest muscles, and insertions of chest tubes ${ }^{(3)}$.

The adverse effects of this painful procedure have not yet been duly investigated, and little is known about the measures applied in intensive care units (ICU) to control pain related to painful procedures. This lack of knowledge may contribute to an increase in postoperative pulmonary complications, such as a decrease in respiratory muscle strength, pulmonary volumes and capacity, as well as reducing the effectiveness of cough and causing an increase in the number of pulmonary infections. These complications interfere with the clinical progression of patients and are considered the main causes of morbidity and mortality in such cases ${ }^{(1)}$.

The scope of analgesic protocols is quite wide, ranging from non-pharmacological techniques, relaxation exercise with opioids, opioids alone ${ }^{(4)}$ and ice packs ${ }^{(5)}$, through to the use of drugs such as morphine and local anesthetics. Some approaches combine various drugs to improve analgesia while reducing their side effects. Systemic multimodal, or balanced, analgesia consists of intravenous administration of non-steroidal anti-inflammatory drugs combined with weak and strong opioids ${ }^{(3)}$.

Various studies have examined medical treatments designed to relieve chest tube removel (CTR) pain, including remifentanyl(6), sulfentanyl(7) fentanyl(8), intravenous paracetamol(9), cold application in combination with indomethacin suppository ${ }^{(10)}$, morphine, subcutaneous bupivacaine and Entonox (nitrous oxide 50\% and oxygen $50 \%$ ), with no statistical difference ${ }^{(11)}$, and morphine and ketorolac, again with no statistical difference ${ }^{(12)}$.

One of the main analgesic techniques consists of the subcutaneous administration of lidocaine, which is used to control pain in several procedures, such as venous and arterial puncture, venous and arterial catheter insertion, and chest tube removal, among others. Nevertheless, patients are often not given analgesics or any other procedure to control pain(13).

As pain is an expected occurrence when drains are removed, analgesics should be administered to patients appropriately before chest tube removal to achieve satisfactory effects. The objective of the present study was to analyze the analgesic effect of $1 \%$ subcutaneous lidocaine combined with multimodal analgesia or an intravenous (IV) analgesic regime by means of systematic assessment of the intensity of pain during chest tube removal following heart surgery.

\section{Methods}

The present study was a randomized controlled clinical trial that was approved by the Research Ethics Committee of the Federal University of Rio Grande do Norte (Universidade Federal do Rio Grande do Norte UFRN), N. 186/05, and registered at the Brazilian Registry of Clinical Trials, no. RBR 8M444Q, in accordance with the Declaration of Helsinki. All participants signed an informed consent form at the preoperative assessment. The study was carried out at the Promater Hospital, in Natal, in the Brazilian state of Rio Grande do Norte (RN), in 2013.

The following parameters were used to calculate the sample size: population size, 354 individuals; type 1 error $(\alpha), 0.05$; test power (1- $\beta), 0.80$; and $20 \%$ difference between the groups. According to these criteria, the sample size ought to be 60 participants, with 30 in each of the two groups. As a function of the inclusion criteria and losses over the course of the study, the final sample was composed by 58 participants, who were allocated to Group I (GI) - experimental $(n=30)$ and GII - control $(n=28)$, by simple random sampling.

The inclusion criteria were as follows: age 35 to 75 years old; without prior experience of chest drainage; to be in the postoperative period after heart surgery with chest tube insertion; to provide surgical access through median sternotomy; to provide hemodynamic stability with signs evaluated by bedside monitoring; American Society of Anesthesiologists (ASA) physical status 2 or 3; and to exhibit appropriate verbal communication and understanding to participate in interviews. To assess the latter, the Ramsay sedation scale was used ${ }^{(14)}$. This scale scores sedation at six different levels, as follows: 1- anxiety and/or agitation; 2- tranquility, cooperation and orientation; 3- response to commands only; 4- brisk response to auditory or painful stimulus; 5- sluggish response to auditory or painful stimulus; and 6- no response. Only individuals at levels $\leq 3$ were included. Individuals who declared a wish to withdraw from the study were excluded, as were individuals who developed postoperative complications, including severe heart and/or respiratory failure and stroke, or who required reoperation from any cause. Figure 1 depicts the flowchart of the study participants. 


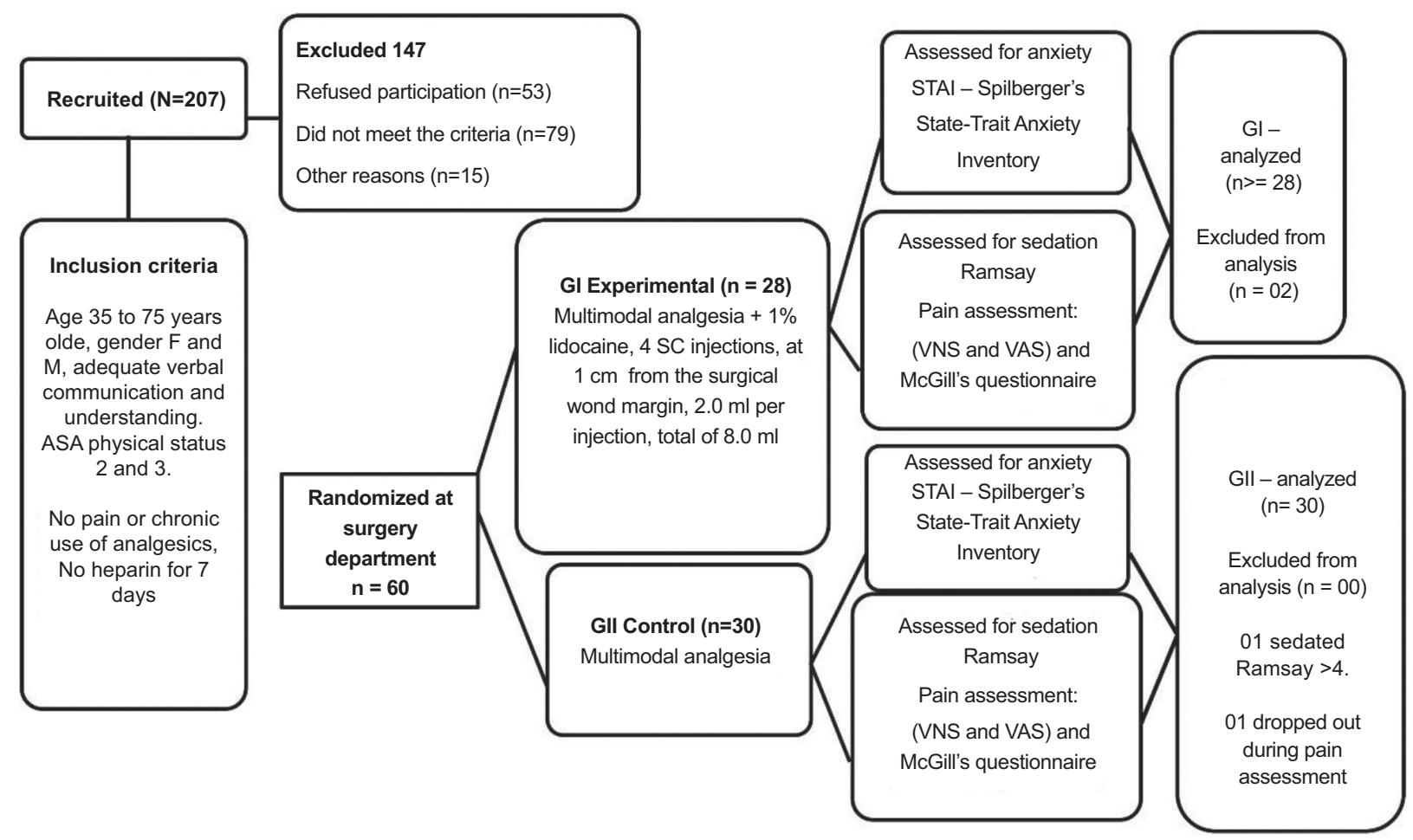

Figure 1 - Flow diagram of the study, Natal, RN, Brazil, 2014

At the preoperative visit, after the informed consent form was signed, all of the participants were trained in the use of a $10-\mathrm{cm}$ visual analog scale(15) (VAS) for pain and were advised to describe the quality of pain using the short-form McGill Pain Questionnaire (descriptors) $^{(16)}$. On that occasion, the participants were also instructed on how to behave upon waking up after surgery at the ICU, as, in order to better assess their pain, it is better for them to be thoroughly acquainted with both instruments. Finally, the participants' levels of anxiety were assessed using STAI (State-Trait Anxiety Inventory) and Spielberger's theoretical framework ${ }^{(17)}$. The doctors and nurses at the institution where the study was conducted established that the chest tubes would be removed 24 hours after surgery. The number, size, and position of the chest tubes were selected according to surgical need. Tube sizes $19 \mathrm{~F}$ and $28 \mathrm{~F}$ are routinely used for chest drainage at the institution where the study was followed.

The individual needs of additional analgesia were recorded for all experimental and control patients following the standardization of the ICU post-operative analgesia.

Before the removal of the chest tubes, the participants were randomly allocated to the study groups by the cardiologists using a computer-based database that had been previously established. In addition to the standard analgesic regime used at the ICU where the study was conducted for patients after heart surgery, the participants in the experimental group were given four subcutaneous injections of $1 \%$ lidocaine at approximately one $\mathrm{cm}$ from the surgical wound margin using $7 \mathrm{~mm}$ in a diamond pattern; the volume of each dose was $2.0 \mathrm{ml}$, for a total of $8.0 \mathrm{ml}$. The participants in GII were only given one multimodal analgesic ${ }^{(3)}$, which consisted of the administration of non-steroidal antiinflammatory drugs combined with weak and strong opioids by IV based on the systematic assessment of the pain intensity (visual analog scale - VAS)(15): pain < 3 (weak analgesic), dipyrone IV $30 \mathrm{mg} / \mathrm{kg}$ every six hours; pain $=4$ to 7 , tramadol IV $50 \mathrm{mg} / \mathrm{kg}$ every six hours; and pain $=8$ to 10 , morphine IV 1 to $2 \mathrm{mg}$. The chest tubes were removed by the surgeon. Following the procedure, nurses were blinded to the composition of the study groups and assessed the participants when the surgeon was not present.

In the statistical analysis, for the descriptive analysis, the categorical data were arranged in tables of absolute and relative frequencies. As the distribution of the quantitative data was not normal, the data were 
expressed as median, minimum, and maximum values. Data with normal distributions were expressed as the mean and standard deviation. For the bivariate analysis, the association among categorical variables relative to the groups was investigated by means of the Chisquared test with Yates's correction for continuity or Fisher's exact test. The Mann-Whitney (U) test was used to compare the medians or means of continuous independent variables relative to the groups.

In all of the analyses, standard $0.05 \mathrm{p}$-values and 95\% confidence intervals were applied.

\section{Results}

The initial sample was comprised of 60 participants. However, two individuals in the control group did not complete the study, with one case requiring reinsertion of the chest tubes and another refusing to participate in the assessments. Therefore, 58 participants were assessed after surgery. Thirty-six (62.1\%) participants were male, and $22(37.9 \%)$ were female; the average age of the sample was 59.78 ( \pm 8.93) years old. The groups did not exhibit significant difference with respect to gender, age, surgery time, hospital stay and ASA physical status. Table 1 describes the distribution of the results with respect to the assessment of anxiety. Most of the participants exhibited low-to-average and mild-to-moderate levels of trait and state anxiety, respectively. Significant association was not observed between the levels of anxiety and the study groups.

With respect to the assessment of pain as a function of lidocaine injection, there was no association between the presence of pain and groups $(p=0.42)$, as Table 2 shows. In addition, the median intensity of pain with respect to lidocaine injection did not differ between the groups $(p=0.27)$

With respect to chest tube removal, no association was observed between group and anxiety level ( $p=$ $0.94)$ or pain before the procedure $(p=0.67)$, as shown in Table 3. The median intensity of pain upon removal of pleural or mediastinal chest tubes did not differ significantly between the groups.

Table 1 - Data corresponding to the participants' trait, state anxiety levels and profile per group, Natal, RN, Brazil, 2014

\begin{tabular}{|c|c|c|c|c|c|}
\hline \multirow[b]{3}{*}{ Age (years) } & \multicolumn{4}{|c|}{ Groups } & \multirow{3}{*}{$\frac{\text { p-value }}{0.75^{\star}}$} \\
\hline & \multicolumn{2}{|c|}{ Experimental } & \multicolumn{2}{|c|}{ Control } & \\
\hline & 60.1 & \pm 8.1 & 59.7 & \pm 9.5 & \\
\hline \multicolumn{6}{|l|}{$\operatorname{Sex}(n-\%)$} \\
\hline Male & 17 & 47.2 & 19 & 52.8 & \multirow{2}{*}{$0.23^{\dagger}$} \\
\hline Female & 13 & 54.2 & 9 & 45.8 & \\
\hline Surgery time (hours - mean \pm stand deviation) & 4.1 & 0.8 & 4.3 & 0.9 & $0.15^{*}$ \\
\hline Hospital stay (days - mean \pm stand deviation) & 7.1 & \pm 0.9 & 7.5 & \pm 0.7 & $0.56^{*}$ \\
\hline \multicolumn{6}{|l|}{ ASA physical status ( $n-\%)$} \\
\hline II & 13 & 44.8 & 19 & 61.3 & \multirow[t]{2}{*}{$0.20^{+}$} \\
\hline III & 16 & 55.2 & 12 & 38.7 & \\
\hline \multicolumn{6}{|l|}{ Trait anxiety $(\mathrm{n}-\%)$} \\
\hline Low & 8 & 53.3 & 7 & 46.7 & \multirow{3}{*}{$0.76^{+}$} \\
\hline Average & 17 & 48.6 & 18 & 51.4 & \\
\hline High & 5 & 62.5 & 3 & 37.5 & \\
\hline \multicolumn{6}{|l|}{ State anxiety $(n-\%)$} \\
\hline Mild & 15 & 51.7 & 14 & 48.3 & \multirow{3}{*}{$0.99^{\dagger}$} \\
\hline Moderate & 13 & 52.0 & 12 & 48.0 & \\
\hline Intense & 2 & 50.0 & 2 & 50.0 & \\
\hline
\end{tabular}

* Mann-Whitney (U) test

+ Chi-Squared test

Table 2 - Sample characterization according to the presence and intensity of pain upon lidocaine injection, Natal, RN Brazil, 2014

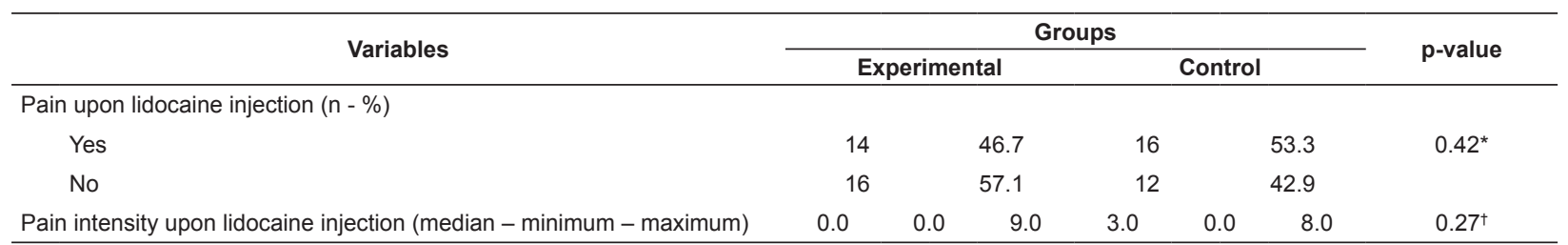

* Chi-Squared test

+ Mann-Whitney $(U)$ test 
Table 3 - Sample characterization according to anxiety level and pain intensity upon chest tube removal, Natal-RN, Brazil, 2014

\begin{tabular}{|c|c|c|c|c|c|}
\hline \multirow{2}{*}{ Variables } & \multicolumn{4}{|c|}{ Groups } & \multirow{2}{*}{ p-value } \\
\hline & \multicolumn{2}{|c|}{ Experimental } & \multicolumn{2}{|c|}{ Control } & \\
\hline Low & 19 & 51.4 & 18 & 48.6 & $0.94^{*}$ \\
\hline Average & 11 & 52.4 & 10 & 47.6 & \\
\hline \multicolumn{6}{|l|}{ Pain before chest tube removal ( $\mathrm{n}-\%)$} \\
\hline Yes & 7 & 50.0 & 7 & 50.0 & $0.67^{*}$ \\
\hline No & 22 & 56.4 & 17 & 43.6 & \\
\hline Pain intensity upon mediastinal chest tube removal (mean \pm stand deviation) & 4.0 & 2.4 & 3.7 & 2.8 & $0.56^{\dagger}$ \\
\hline Pain intensity upon pleural chest tube removal (mean \pm stand deviation) & 6.6 & 3.4 & 6.7 & 3.4 & $0.92^{\dagger}$ \\
\hline
\end{tabular}

* Chi-Squared test

+ Mann-Whitney (U) testeT

\section{Discussion}

There is evidence that adequate pain control is significantly beneficial for patient comfort. Although multimodal analgesia combined with lidocaine is considered an option for chest tube removal, this therapy was not effective in the present study.

Although no association was observed between trait and state anxiety and group, and despite the orientations and psychological support provided by the nurses as a part of the routine care before the procedure, almost half of the participants exhibited moderate anxiety.

Almost one-third of the participants reported the presence of pain before chest tube removal. Both groups localized the majority of their pain to the sternotomy site, as well as the site of chest tube insertion, particularly in the case of the pleural drains, followed by the saphenectomy site. These findings agree with previous studies, where pain occurred at the sternotomy site up to postoperative day three ${ }^{(18-19)}$.

There was no significant difference in pain associated with the subcutaneous administration of lidocaine between the groups. In this regard, it is worth noting that the intensity of pain reported was mild, which might be related to the use of multimodal analgesia. According to the literature(20), discomfort and pain during the subcutaneous administration of lidocaine is reported by patients as a whole. These symptoms might be related to the needle gauge, anesthetic administration speed, injected solution volume or temperature, patient profile, or the low $\mathrm{pH}$ of the anesthetic.

The groups did not exhibit significant differences in pain associated with the procedure for CTR. However, the participants in the experimental group (GI) qualified the pain upon removal of mediastinal chest tubes as intense, followed by moderate in almost one-third of the cases.
These findings are supported by several clinical trials and indicate that patients feel moderate-to-intense pain even when strong analgesics, such as morphine, and local anesthetics, including lidocaine, are administered. Most studies found that patients felt moderate-tosevere pain during chest tube removal despite the administration of morphine or local anesthetics(21).

One study compared the efficacy of remifentanyl $0.5 \mathrm{mg} / \mathrm{kg}$ versus placebo for alleviating pain due to chest tube removal. The results revealed that the patients receiving remifentanyl exhibited significantly less pain than did those receiving a placebo at drain removal(6). In another study ${ }^{(7)}$ significantly lower pain scores were reported in the groups treated with fentanyl $2 \mu \mathrm{g} / \mathrm{kg}$ IV or sufentanyl $0.2 \mu \mathrm{g} / \mathrm{kg}$ IV, compared with the patients in the control group who were given $2 \mathrm{ml}$ of normal saline.

Chest tube removal and pleural drains in particular are considered a determinant factor for the development of intense pain after cardiac surgery. It is also observed that removal of pleural chest tubes is more painful compared with mediastinal drains(2). Furthermore, some patients report that the pain or the discomfort caused by the procedure is one of the worst experiences in ICU. Insertion of pleural drains is unavoidable during pleurotomy and causes traumatic chest injuries due to the perforation of the intercostal muscles and parietal pleura, which interferes with the respiratory movements and the position of the pleural drains(22-23). Another study(24) demonstrated that patients with subxiphoid pleural drains reported less pain compared with the ones with intercostal insertion. Similar findings were reported(25) and described a technique of subxiphoid pleural drain insertion to reduce postoperative discomfort due to the chest tube friction against the intercostal space. 
In our study, the words (descriptors) used by the participants to describe pain were pressing, sharp, pricking, and burning, and the most common site of pain was the drain site $(65.0 \%)$. Using the same instrument and type of population, one study ${ }^{(2)}$ reported that the words used to describe the pain caused by chest tube removal were fearful $(44.8 \%)$, sharp and tender $(40.3 \%)$, and hot-burning using the same instrument in the same population.

Regarding the effectiveness of other nonpharmacological therapies for pain control in the CTR, cold application, which seemed to be a noninvasive and safe way to reduce pain, in a systematic review that analyzed data from 426 patients, 05 trials showed conflicting results $^{(5)}$. However, the study of Demir and Khorshid(26) found that cold application reduced patients' intensity of pain due to CTR but did not affect anxiety levels or the type of pain. They nevertheless recommended cold as a pain-relieving technique during CTR.

As a possible limitation of the present study, we believe that the fact that the number of participants may have some kind of influence on the results. Therefore, the findings cannot be generalized to other patients who experience CTR. It is recommended that the study be repeated with more patients who experience CTR for other reasons. The present study was designed in two groups; as a result, the possible placebo effect on the patients' pain perception was not identified. It is recommended that a similar study in three groups be conducted to exclude the placebo effect. In our study, patients might have responded differently to pain based on their physical condition, emotional and cultural states. Further studies in different settings are suggested.

\section{Conclusion}

Thus, the present study suggests that the analgesic effect of the subcutaneous administration of $1 \%$ lidocaine combined with multimodal analgesia is less effective and subcutaneous injections are less effective in relieving pain.

\section{References}

1. Charnock Y, Evans D. Nursing management of chest drains: a systematic review. Aust Crit Care. 2001;14(4):156-60.

2. Puntillo KA, Ley SJ. Appropriately timed analgesics control pain due to chest tube removal. Am J Crit Care. 2004;13(4):292-301.
3. Kelet $H$, Dahl JB. The value of "multimodal" or "balanced analgesia" in postoperative pain treatment. Anesth Analg. 1993;77(5):1048-56.

4. Friesner SA, Miles Curry D, Moddeman GR. Comparison of two pain-management strategies during chest tube removal: Relaxation exercise with opioids and opioids alone. Heart Lung. 2006;35(4):269-76.

5. Chen YR, Hsieh LY. The effectiveness of a cold application for pain associated with chest tube removal: a systematic review. $\mathrm{Hu} \mathrm{Li} Z \mathrm{Za}$ Zhi. $2015 ; 62(1): 68-75$.

6. Casey E, Lane A, Kuriakose D, McGeary S, Hayes $\mathrm{N}$, Phelan $\mathrm{D}$, et al. Bolus Remifentanil for chest drain removal in ICU: a randomized double-blind comparison of three modes of analgesia in post-cardiac surgical patients. Intensive Care Med. 2010;36(8):1380-5.

7. Joshi VS, Chauhan S, Kiran U, Bisoi AK, Kapoor PM. Comparison of analgesic efficacy of fentanyl and sufentanil for chest tube removal after cardiac surgery. Anna Card Anaesth. 2007;10(1):42-5.

8. Golmohammadi M, Sane SH. Comparison of fentanyl with sufentanil for chest tube removal. Iranian Cardiovasc Res J. 2008;2(1):42-7.

9. Demir Y, Khorshid L. The Effect of Cold Application in Combination with Standard Analgesic Administration on Pain and Anxiety during Chest Tube Removal: A SingleBlinded, Randomized, Double-Controlled Study. Pain Manag Nurs. 2010;11(3):186-96.

10. Payami MB, Daryei N, Mousavinasab N, Nourizade E. Effect of cold application in combination with Indomethacin suppository on chest tube removal pain in patients undergoing open heart surgery. Iran J Nurs Midwifery Res. 2014;19(1):77-81.

11. Akrofi M, Miller S, Colfar S, Corry PR, Fabri BM, Pullan $M D$, et al. A randomized comparison of three methods of analgesia for chest drain removal in postcardiac surgical patients. Anesth Analg 2005;100(1):205-9.

12. Puntillo K, Ley SJ. Appropriately timed analgesics control pain due to chest tube removal. Am J Crit Care. 2004;13(4):292-302.

13. Chaves LD, Pimenta CAM. Postoperative pain control: comparison among analgesic methods. Rev. Latino-Am. Enfermagem. 2003:11(2):215-9.

14. Ramsay MA, Savege TM, Simpson BR, Goodwin R. Controlled sedation with alphaxalone-alphadolone. $\mathrm{Br}$ Med J. 1974;2(5920):656-59.

15. Jensen MP, Karoly P, Braver R. Postsurgical pain outcome assessment. Pain 2002;99:101-9.

16. Melzack R. The short-form McGill Pain. Pain 1987;30:191-7. 
17. Spielberger $C D$, Gorsuch $R L$, Iushene RE. Inventário de Ansiedade Traço-Estado - IDATE: Manual de Psicologia Aplicada [State-Trait Anxiety Inventory - STAI: Manual of Applied Psychology]. Rio de Janeiro: CEPA; 1979.

18. Mueller XM, Tinguely $F$, Tevaearai HT, Revelly JP, Chioléro $R$, von Segesser LK. Pain location, distribution, and intensity after cardiac surgery. Chest. 2000;118(2):391-6.

19. Giacomazzi CM, Lagni VB, Monteiro MB. A dor pósoperatória como contribuinte do prejuízo na função pulmonar em pacientes submetidos à cirurgia cardíaca Postoperative pain as a contributor to pulmonary function impairment in patients submitted to heart surgery. Rev Bras Cir Cardiovasc. 2006;21(4):386-92.

20. Cepeda MS, Tzortzopoulou A, Thackrey M, Hudcova J, Arora Gandhi P, Schumann R. Adjusting the $\mathrm{pH}$ of lidocaine for reducing pain on injection. Cochrane Database Syst Rev. 2010;8(12):CD006581.

21. Bruce EA, Howard RF, Franck LS. Chest drain removal pain and its management: a literature review. J Clin Nurs. 2006;15(2):145-54.

22. Jakob H, Kamler M, Hagl S. Doubly angled pleural drain circumventing the transcostal route relieves pain after cardiac surgery. Thorac Cardiovasc Surg. 1997;45(5):263-4.

23. Lancey RA, Gaca C, Salm TJV. The use of smaller, more flexible chest drains following open heart surgery. Chest. 2001;119(1):19-24.

24. Guizilini S, Bolzan DW, Faresin SM, Ferraz RF, Tavolaro K, Cancio AA, et al. Pleurotomy with subxyphoid pleural drain affords similar effects to pleural integrity in pulmonary function after off-pump coronary artery bypass graft. J Cardiothorac Surg. 2012;25:7-11.

25. Riebman JB, Yurvati AHO, Laub GW. Improved technique for pleural drain insertion in cardiovascular surgery. J Cardiovasc Surg. 1994;35(6):503-5.

26. Demir Y, Khorshid L. The effect of cold application in combination with standard analgesic administration on pain and anxiety during chest tube removal: a singleblinded, randomized, double-controlled study. Pain Manag Nurs. 2010; 11(3):186-96.

\section{Erratum}

Where was written:

"Conclusion: the present study suggests that the analgesic effect of the subcutaneous administration of $1 \%$ lidocaine combined with multimodal analgesia is most efficacious."

Now Read:

"Conclusion: the present study suggests that the analgesic effect of the subcutaneous administration of $1 \%$ lidocaine combined with multimodal analgesia is less effective." 